\title{
INFLUENCING FACTORS OF BOREHOLE FAILURE IN BEDDING PLANE OF A RESERVOIR
}

\author{
Md. Shamsuzzoha \\ TGTDCL, 105 Kazi Nazrul Islam Avenue, Kawranbazar, Dhaka-1215 \\ Corresponding e-mail: zoha.shamsu@gmail.com
}

\begin{abstract}
Borehole instability during drilling is common in shale formation. Weak bedding plane in borehole is critical in understanding in-situ stress and borehole instability. Unified decision about the plane of weakness and failure of borehole on shale has yet to be fully realized by the industry, particularly because borehole stability has not been well addressed. This research was based on a linear elastic and isotropic model for stresses around the wellbore with the aim of trying to understand the general behaviour of inclined borehole failure due to bedding plane. Using Aadnoy et. al (2009)'s model, this paper discussed mechanical wellbore stability and plane of weakness of shale formation. This paper investigated three major factors firstly, borehole failure of bedding plane, secondly it introduced optimized well path. Thirdly, it analysed whether well data was present at a safe position or bedding exposed positions. This paper also analysed the $3 D$ effect of attack angle changing azimuth with a constant inclination on bedding plane. This paper argues that bedding exposed does not only depend on inclination but also depend on dip of the formation, attack angle and azimuth. It also found the different value of attack angle of up dip and down dip position of Aadnoy model and addressed way to solve the existing difficulty.
\end{abstract}

Keywords: Drilling, failure Plane, attack angle, Borehole Stability, In-Situ Stress, Bedding Plane

\section{INTRODUCTION}

The increasing demand of well bore stability analysis during the planning stage of a field arises from economic consideration and the escalating use of deviated, extended reach and horizontal wells. The purpose of wellbore stability modelling is to create a safe operating window of annular pressures (mud pressures and mud weight) such that the designed fluid is high enough to ensure wellbore stability and enough to ensure no loss of fluid, wellbore failure. Generally, Drilling engineer needs to know the borehole failure criteria and influencing factors of bore failures before planning stage and during drilling operation. Problems generally build up in time, starting with the fragmentation of the borehole wall, followed by transfer of the fragments to the annulus and finally if hole cleaning is insufficient, culminating in such difficulties as a tight hole, packing off, filling of the hole, stuck pipe etc. To develop a model, well bore collapse/fracture, in-situ stress, pore pressure, in-situ stress orientation, wellbore trajectory, bedding and weak plane directions and relevant rock strength data need to know.

Sedimentary rocks have a laminated structure with directional elastic properties as well as directional shear and tensile strengths. Anderson, 1951 and Jaeger, $1960^{1,11}$ gave a thorough analysis of the various loading scenario that explain bedding plane failure. A common way to model shear failure using Jaeger's approach is to use the Mohr Coulomb failure model, but vary the cohesive strength and the angle of internal friction, depending on the loading relative to bedding plane inclination. On the basis of Jaeger, the plane of weakness was introduced in the oil industry by Aadnoy et. al. $2009^{2}$.He also investigated prime factors of weak bedding plane bore hole failure. They examined the effects of wellbore inclination, anisotropic elastic rock properties, anisotropic stresses, and anisotropic rock strength for the modelling of highly inclined boreholes. Before doing the massive drilling, the estimation of insitu stress is needed by applying pilot drilling, can be made borehole orientation and azimuth.

The major factors for bore hole failure includes Insitu stress and direction, wellbore trajectory, rock strength, tectonic condition, Pore Pressure, anisotropy, relative position of bore hole, Bedding plane and attack angle. In-situ stresses are caused by the weight of the rock and by the confining lateral restraints. The In-situ stresses can be resolved into a vertical (overburden, $\sigma_{\mathrm{v}}$ ) and two horizontal stresses such as maximum stress $\left(\sigma_{\mathrm{H}}\right)$ and minimum stress $\left(\sigma_{\mathrm{h}}\right)$ which are generally unequal. Layered rocks such as shale often exhibit different properties along or across bedding planes. According to Aadnoy et.al. ${ }^{2}$, rock strength is high when force vectors are applied at a high angle to bedding. This research works assumed for developing model that linearisotropic plane strain conditions, all in-situ stresses are principal and directed horizontally and vertically. The key in this analysis is that when a well is drilled, the rock surrounding the hole must take the load that was 
previously taken by the removed rock. As a result stress concentration increases around the wall. If the rock is not strong enough, the borehole fails.

We get one of the significant borehole failures in case of weak bedding Plane. The optimum well path increased mechanical borehole stability that is the borehole orientation that maximizes the difference between the fracture and the collapse pressure. Based on hoop stress analysis, mathematical expression to optimize well path under in-situ stress state is defined by paper Islam and Al-Ajmi ${ }^{7,10}$.

\section{FACTORS FOR FAILURE PLANE AND BEDDING PLANE}

Failure plane means in what plane the wellbore/specimen fail. One can analyse failure plane by Mohr-coulomb and tri-axial test (under different load condition) and can be determined angle of fracture $(\alpha)$ from a specimen shown in Fig. 1. This matter is to be complex when one thinks on the underground condition; because of complexity of in-situ stresses and pore pressure that are acting and changing the matter due to depletion of the reservoir. Here, $\alpha$ is the angle between applied force and failure plane during tri-axial coretesting and $\beta$ is the angle between applied force and bedding plane during tri-axial core testing.

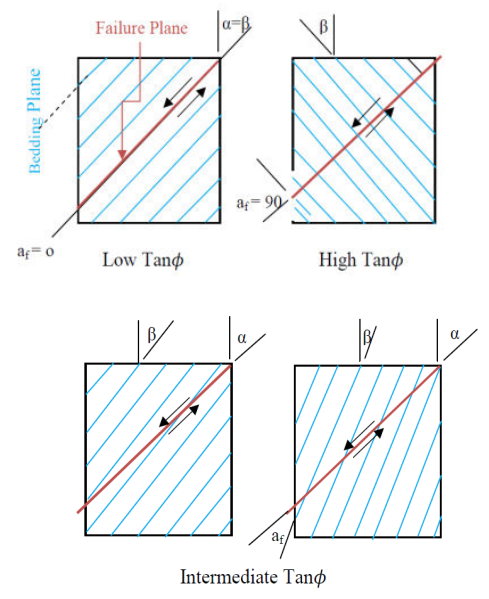

Figure 1. Failure plane Vs Bedding plane with variation of angle $^{1,2,9}$.

One thing for reader does not confuse about $\gamma$ and $\beta, \gamma$ is related for wellbore inclination from vertical, on the other hand $\beta$ is related to Core-plug. If any one wants to compare attack angle and $\beta$, they are equivalent, but they are considered in different positions. Where, $\phi$ is friction angle and $a_{\mathrm{f}}$ is angle between failure and bedding plane. So the array of bedding plane, borehole position and the dip/strike angle of formation are important parameters if anyone wants to apply the in- situ stresses equations for determining failure criterion of bedding plane, rock strength and wants to develop models of wellbore failure.

\section{MODEL REVIEW}

Elastic properties like bulk modulus, Young's modulus, and poison's ratio, show directional properties $^{2-5,9,11}$. Rock strength is high when force vectors are applied at a high angle to bedding. At lower angles, on the order of $15^{\circ}$ and $30^{\circ}$, strata compressive strength is low, then rock failure occur along bedding planes. This type of rock behaviour is often termed 'Planes of weaknesses'. Bedding planes of shale mainly affect high angle and horizontal wells drill close to the minimum horizontal stress direction ${ }^{2}$.
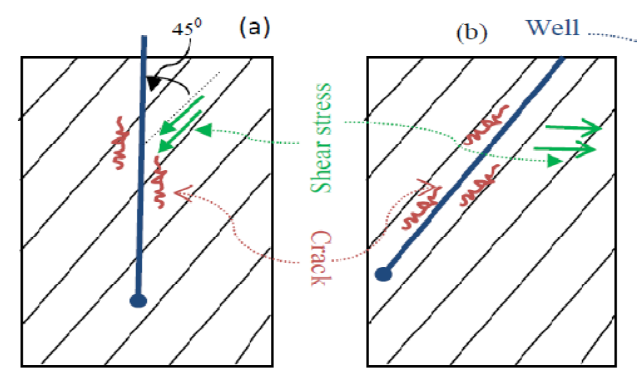

(c)

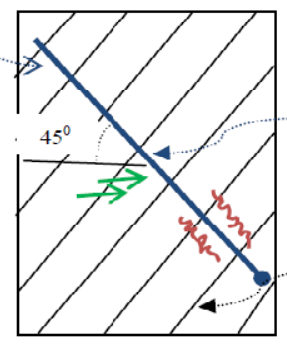

(e)

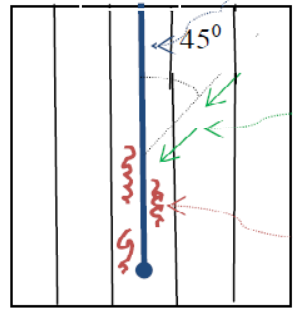

(d)

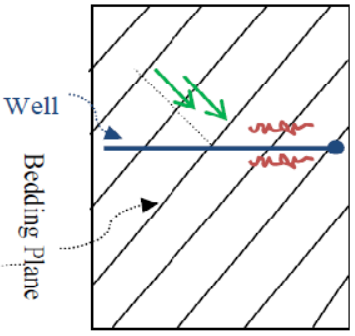

(f)

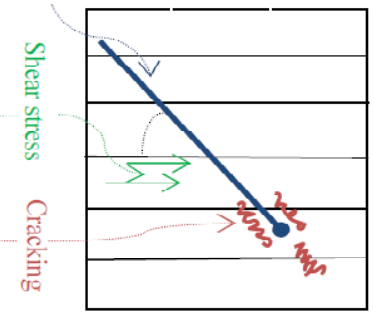

Figure 2. Wells drills into different angle to bedding plane ${ }^{1,10}$.

Four failure criterions are reviewed to access borehole stability and failure related to bedding plane, namely Mohr-coulomb, Drucker-Prager, Mogi-Coulomb and modified Lade criteria ${ }^{1}$. Results indicate that the 
modified Lade, Mogi-Coulomb criteria tend to be more realistic than the Mohr-coulomb and Druck-Prager criteria for these evaluations. This paper considers only mechanical failure instead of chemical failure. Mechanical wellbore instability is caused by applying mud of insufficient weight, which creates greater hoop stresses around the borehole wall and excessive hoop stresses. Critical parameters are plane of weakness in the rock strength, the relative normal stress values on the borehole and the relative angle between the borehole and bedding Plane ${ }^{2-7}$. Haimson, Herrik and Aadnoy ${ }^{1}$ conclude that collapse occurs at the position of the borehole that corresponds to the direction of the least in-situ stress, normal to the axis of the hole. They also concluded that if the least in-situ stress is normal to the plane of the borehole axis and the axis is normal to the bedding plane is different, the directional shear strength come into play and potential collapse will occur $15^{0}<\beta<35^{0}$.

\section{Physical model of bedding plane failure}

Two conditions determine whether the rock fails along a weakness plane or not; the relative magnitude of the two normal stresses and the angle between the borehole and the bedding plane. In general, for any combination of weak bedding plane \& hitting (attack) angle orientation, the evolved shear stress direction along the weak bedding plane pose a risk for initiating material failure. The physical model by representing different attack angle is shown in Fig. $2^{10}$.

The most important features will be in the attack angle between the borehole and the weak bedding plane which evolve shear stress direction along the bedding plane pose a risk of initiating material failure ${ }^{10}$.

\section{BOREHOLE FAILURES WITH DEPTH}

Borehole collapse and fracture occurs at different depth and condition is shown in Fig. $3^{1,2,4,6}$. A typical fracturing (horizontal fracture) of the wellbore in shallow well shown in fig. 3a, where the overburden is being lifted .The axial stress $\sigma_{\mathrm{z}}$ goes tensile, while $\sigma_{\theta}, \sigma_{\mathrm{r}}$ remain in a compressive stress. Shear effects occur between $\left(\sigma_{\theta}, \sigma_{\mathrm{z}}\right),\left(\sigma_{\theta}, \sigma_{\mathrm{r}}\right)$, and $\left(\sigma_{\mathrm{r}}, \sigma_{\mathrm{z}}\right)$ because of large stress differences. No rock pieces will be released because of both tensile and shear stresses cause fracturing act outward from the borehole. Fig. 3b illustrates the fracturing of deeper well, where vertical fracturing is occurred. Here radial and axial stresses are compressive and circumferential or hoop stress is tensile in nature. A borehole collapse is described in Fig.3c, this typical drawdown problem, here both axial and tangential stress goes compressive and radial effective stress goes in tension. It is visualized that wellbore sometimes fails in tension around a circumference shown in fig. $3 \mathrm{c}$ this case presence of radial failure aids the shear stresses in releasing piece of rocks from wellbore. The borehole failure can be determined by the comparing of core plug and the real borehole stress condition in the underground condition.
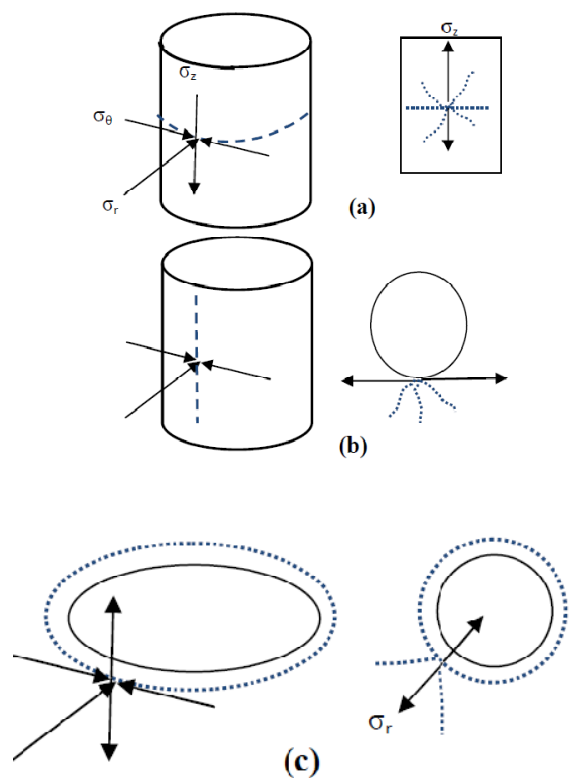

(c)

Figure 3. Characteristic of borehole failure $e^{4,5,6}$

\section{DEVIATED BOREHOLE IN BEDDED ROCK}

Figure 4 shows a deviated borehole in bedded rock ${ }^{1,2}$. Two infinitesimally small pieces of rocks are shown on the borehole wall. The borehole typically fail at $\theta=0^{0}$ (Case A) or $90^{\circ}$ (Case B). If the applied stress in the $\mathrm{x}$ direction is the smallest, the borehole fail in case of $\mathrm{A}$ and $\mathrm{y}$ direction is the smallest applied stress, borehole fail in Case of B. For atypical collapse, the radial stress is the smallest, according to Mohr-coulomb criterion; we can avoid axial stress of laboratory data (as an intermediate pressure). The radial stress is the minor principal stress and the tangential stress (hoop stress) is the major principal stress.

The dial stress normally occurs to principal stress direction, tangential stress does not act exactly to principal stress direction because some shear stress components change the direction slightly. The equivalent (as well) core plug shown in Fig. 4, incase of $\mathrm{A}$, the tangential stress acts parallel to the bedding plane, Therefore $\beta=0^{0}$, regardless of inclination between borehole and bedding plane, one shear data set are applied for all borehole angles. In case of B, tangential stress applies at an angle with respect to the bedding plane and values now $\beta=\gamma$, But directional shear stress come into account with respect to bedding plane. 


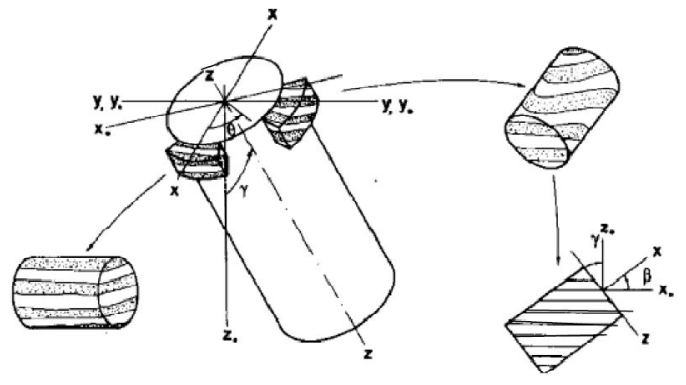

C'asA at $\theta=0^{0}$

CasB at $\theta=90^{\circ}$

Figure 4.Test Plug bedding plane at related to wellbore position $^{1,2,4}$.
The layered rock at the borehole wall has shown as a core plug. For the case of A, the weakness plane does not expose and a stable borehole exists. For the case of $\mathrm{B}$, the plane of weakness has exposed for certain wellbore/bedding plane inclinations, leading to an unstable borehole. The bedding inclination of the core plug $(\beta)$ is equivalent to the borehole versus bedding inclination for the actual well $\left(\mathrm{a}_{\mathrm{at}}\right)$ in Fig. 4, if the in-situ stress tensor is aligned with the bedding plane, the inclination $\gamma$ also applies to the bedding plane. For a dipping bedding plane, the relative orientation between borehole and bedding plane is: $\gamma-\mathrm{k}_{\mathrm{dip}}$, where $\mathrm{k}_{\mathrm{dip}}$ is the formation dip. If there is a small stress contrast between $\sigma_{x}$ and $\sigma_{y}$, within the sensitive borehole/bedding orientation, other failures such as bedding weakness may occur. This paper took stress of states equation and

\begin{tabular}{|c|c|c|c|c|c|c|}
\hline \multicolumn{4}{|c|}{ Input Value } & \multicolumn{3}{|c|}{ Output Value } \\
\hline $\begin{array}{l}\text { Stress State } \\
\text { and Dip }\end{array}$ & $\begin{array}{l}\text { Stress } \\
\text { value }\end{array}$ & Unit & $\begin{array}{l}\text { Relative } \\
\text { value }\end{array}$ & Type of Series & Strike slip & Unit \\
\hline $\begin{array}{l}\text { Overburden } \\
\text { Stress }\end{array}$ & 25 & $\mathrm{Kpa} / \mathrm{m}$ & 0.86 & $\begin{array}{c}\text { Number of well } \\
\text { data (from image } \\
\log \text { ) }\end{array}$ & 19 & no \\
\hline $\begin{array}{l}\text { Maximum } \\
\text { horizontal } \\
\text { stress }\end{array}$ & 29 & $\mathrm{Kpa} / \mathrm{m}$ & 1.00 & $\begin{array}{l}\text { Testing bedding } \\
\text { exposed from any } \\
\text { field data }\end{array}$ & $\begin{array}{l}\text { Bedding } \\
\text { exposed }\end{array}$ & \\
\hline $\begin{array}{l}\text { Minimum } \\
\text { horizontal } \\
\text { stress }\end{array}$ & 20 & $\mathrm{Kpa} / \mathrm{m}$ & 0.69 & \multirow[t]{4}{*}{ Optimum well path } & \multirow{4}{*}{$\begin{array}{l}\text { Optimum } \\
\text { well path } \\
\text { strike slip } \\
\text { from } \\
\text { SigmaH }\end{array}$} & 48.214 \\
\hline $\begin{array}{l}\text { Formation } \\
\text { Dip }\end{array}$ & 53 & Deg. & 0.925 & & & Degree \\
\hline \multirow{2}{*}{$\begin{array}{l}\text { Test any field } \\
\text { Data (For } \\
\text { Bedding } \\
\text { exposed) } \\
\end{array}$} & $\begin{array}{l}\text { Attack } \\
\text { angle }\end{array}$ & Unit & $\underset{\mathrm{h}}{\mathrm{Azimut}}$ & & & \\
\hline & 25 & Deg. & 28 & & & \\
\hline \multicolumn{3}{|c|}{ Calculate Bedding exposed } & & \multicolumn{3}{|c|}{ Number of well Data } \\
\hline \multicolumn{3}{|c|}{ Calculate Optimum Well Path } & & \multicolumn{3}{|c|}{ Test Field Data Bedding Exposed } \\
\hline
\end{tabular}

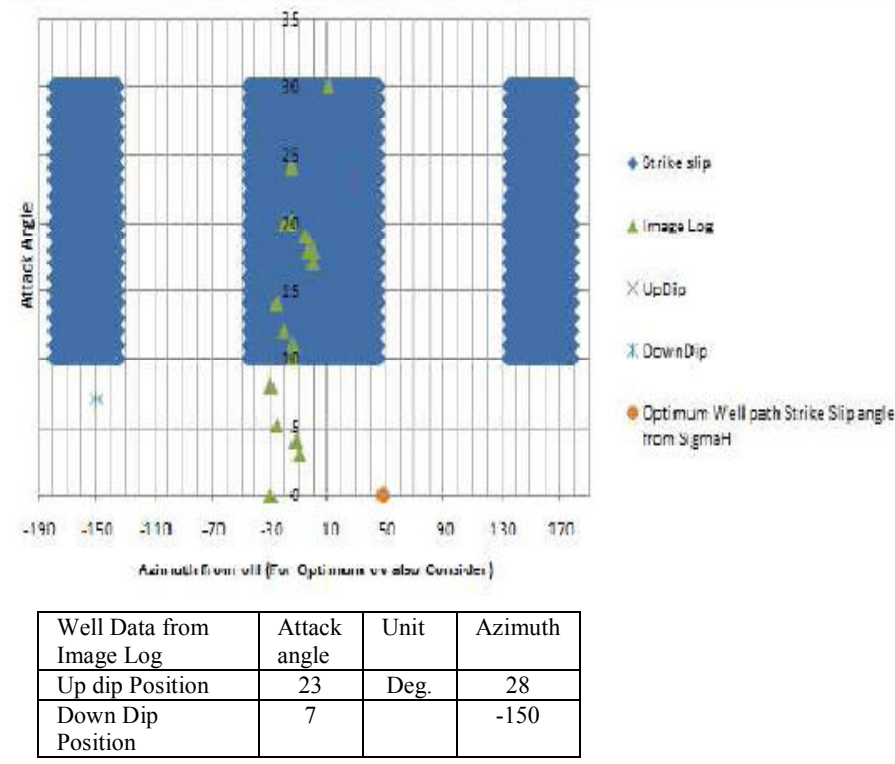

Figure 5. Model view and user input (Spread sheet) ${ }^{1}$.

Journal of Mechanical Engineering, Vol. ME 45, No. 1, June 2015

Transaction of the Mechanical Engineering Division, The Institution of Engineers, Bangladesh 
field data from Aadnoy et.al. ${ }^{2}$ The MSc. thesis at University of Stavanger ${ }^{1}$ has incorporated some parameters of the model which is developed by Aadnoy $^{2}$. The limitation of the incorporation parameter of this model assumed linear elastic rock, integer of inclination angle and $0.5 \mathrm{x}$ integer of Azimuth. This model can run even minimum value of that if the computer has capacity to run, otherwise one can have to take time to obtain the result.

\section{FIELD CASE DATA AND MODEL DEVELOPMENT}

This paper reproduced the result of Aadnoy et.al. ${ }^{2}$ model by the following spread sheet in Fig 5 and introduced optimum well path. This research got almost similar result of paper ${ }^{2}$ and ran model with the formation dip angle. The result has shown that the formation dip would have affect bedding exposed areas. This research work obtained the angle of optimum well path was about 48.20 from maximum principal stress $\left(\sigma_{\mathrm{H}}\right)$ by applying Alajmi, Islam ${ }^{7,10}$ equations. This output seemed to be close to the Aadnoy et.al. ${ }^{2}$ research results that was $45^{\circ}$ from the maximum horizontal stress. I got attack angle $67^{\circ}$ (shown in 3D Fig. 6) that definitely differed from Aadnoy et.al. ${ }^{2}$ result. Their well direction data were azimuth $\mathrm{N} 60^{\circ} \mathrm{E}$, well inclination $30^{\circ}$, strike $\mathrm{S} 50^{\circ} \mathrm{E}$ and $\operatorname{dip} 53^{\circ} \mathrm{SW}$. So it has to be needed further research about the conflict of Aadnoy ${ }^{2}$ and my findings. Any user can introduce field data to obtain their different values such as type of fault, bedding exposed and safe positions, optimum well path, no of well data by applying this enhanced model. The Table 1 and 2 has shown the field data and different states of stress condition of Aadnoy ${ }^{2}$ model.

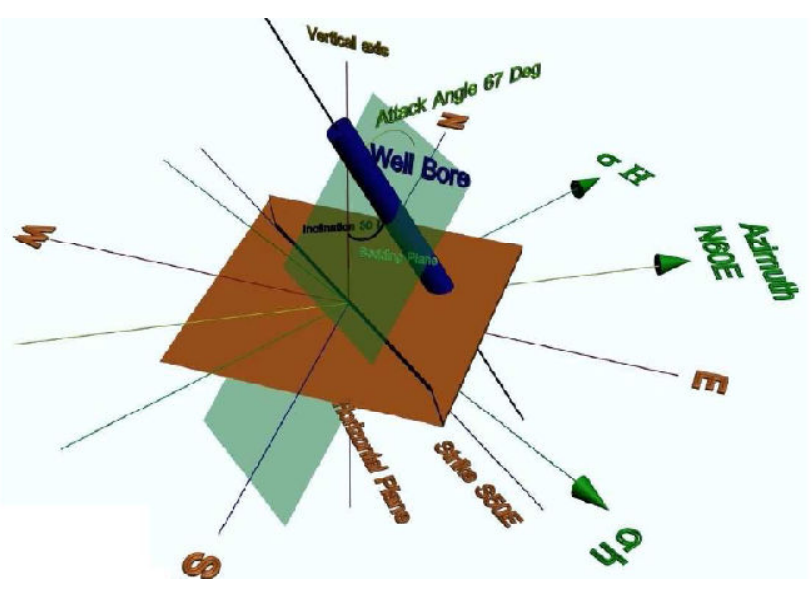

Figure $6.3 \mathrm{D}$ view of filed data ${ }^{1,2}$.
Table 1. Stress of States ${ }^{2}$

\begin{tabular}{|l|l|l|l|}
\hline $\begin{array}{l}\text { Stress } \\
\text { States }\end{array}$ & $\begin{array}{l}\text { Normal } \\
\text { Fault }\end{array}$ & $\begin{array}{l}\text { Strike/Slip } \\
\text { Fault }\end{array}$ & $\begin{array}{l}\text { Reverse } \\
\text { Fault }\end{array}$ \\
\hline$\sigma_{\mathrm{v}}, \sigma_{\mathrm{H}}, \sigma_{\mathrm{h}}$ & $1,0.8,0.8$ & $0.8,1.0,0.8$ & $0.8,1,1$ \\
\hline$\sigma_{\mathrm{v}}, \sigma_{\mathrm{H}}, \sigma_{\mathrm{h}}$ & $1,0.9,0.8$ & $0.9,1,0.8$ & $0.8,1,0.9$ \\
\hline
\end{tabular}

Table 2. BC Well Data ${ }^{1,2}$

\begin{tabular}{|c|c|c|}
\hline Parameter & Magnitude & Source \\
\hline Azimuth & $\mathrm{N} 60^{\circ} \mathrm{E}$ & planned \\
\hline Inclination & 30 Deg. & planned \\
\hline Porepressure, $\mathrm{Pp}$ & $\begin{array}{c}1125 \\
\mathrm{Kg} / \mathrm{m}^{3}\end{array}$ & Drilling record \\
\hline $\begin{array}{l}\text { Overburden Pressure } \\
\text { Gradient, } \sigma_{v}\end{array}$ & $\begin{array}{l}25 \mathrm{Kpa} / \mathrm{m} \\
(1.1 \mathrm{psi} / \mathrm{Ii})\end{array}$ & Density Log \\
\hline $\begin{array}{l}\text { Maximum Horizontal } \\
\text { Pressure Gradient, } \sigma_{\mathrm{H}}\end{array}$ & $\begin{array}{l}29 \mathrm{Kpa} / \mathrm{m} \\
(1.3 \mathrm{psi} / \mathrm{ft})\end{array}$ & $\begin{array}{l}\text { Aadnoy } \\
\text { et.al.2009 }\end{array}$ \\
\hline $\begin{array}{l}\text { Minimum Horizontal } \\
\text { Pressure Gradient, } \sigma_{\mathrm{h}}\end{array}$ & $\begin{array}{l}20 \mathrm{Kpa} / \mathrm{m} \\
(0.94 \mathrm{psi} / \mathrm{ft})\end{array}$ & $\begin{array}{l}\text { Aadnoy } \\
\text { et.al.2009 }\end{array}$ \\
\hline $\begin{array}{l}\text { Maximum Horizontal } \\
\text { Stress Oricntation }\end{array}$ & $\mathrm{N} 32^{0} \mathrm{E}$ & $\begin{array}{c}\text { Borehole Breakout } \\
\text { anlalysis }\end{array}$ \\
\hline Strikc Dip, $S_{p}$ & $\mathrm{~S} 50^{\circ} \mathrm{E}$ & Image Log \\
\hline Dip, $\mathrm{K}_{\text {dip }}$ & $53^{0} \mathrm{SW}$ & Image Log \\
\hline
\end{tabular}

\section{RESULTS AND DISCUSSION}

I got different bedding exposes position in case of different fault regime like normal, strike and reverse fault regime during running the model into the spread sheet. If the angle between borehole and bedding is zero or 90 degrees, then the wells would be more stable according to this research. This study provided invaluable pre-drill wellbore stability analysis of a complex geological structure. This study shows the different influencing factors that planes of weakness in bedded rocks may lead to severe borehole collapse problems. However, there are combination of wellbore inclinations and azimuth, where the weak plane does not expose to failure in the three dimensional space. High tectonic in-situ stress in one direction, the borehole may be made very stable toward collapse by inclining it in the direction of the least in-situ stress ${ }^{2,3,4}$, hence plane of weakness does not come into play at all. On the other hand inclining the borehole in the direction of maximum horizontal in-situ stress gives the conditions for the weakness plane to apply, with the resultant of collapse problems between 10 and $35^{\circ}$ inclination. Generally deeper the well, the more likely the borehole is to become sensitive towards collapse.

According to M-C shear failure theory and Jaeger's weakness plane theory ${ }^{2}$ found that more inclination is sensitive for collapse. The weakness plane makes the 
rock strongly sensitive towards collapse in the range of 10 and $35^{\circ}$ inclinations for relax depositional basin for laminated rocks. In general, the fracturing gradient decreased with increased borehole inclination ${ }^{4}$.

Azimuth is the angle of well direction from true north (or sometimes taken from $\sigma_{\mathrm{H}}$ ) and taken positive with clockwise from north normally. The Fig. 7 showed the effect of attack angle with changing the azimuth. It is found that invariability of inclination, attack angle changed with the azimuth. So it is the most important factor for testing the bedding exposed position with different azimuth under the constant inclination. It is also found that lowest value of attack angle is on the down dip position and the highest value on the up-dip position.
Dip and strike line define the orientation of plane in the three dimensional space. Bedding plane is a surface that separates one stratum, layer, or bed of stratified rock from another. The attack angle is the angle between the wellbore and the bedding plane. So, Drilling engineer and geologist need to know clear dimensional view of the well bore on the underground for determining the failure condition of the wellbore. Dip is a formation properties with relate to strike direction, so attack angle is a function of dip and strike also, both are geological properties. Dip and strike give true picture of the underground with $3 \mathrm{D}$ view of a well ${ }^{1}$. Aadnoy et.al. ${ }^{2}$ paper did not address about the effect of attack angle and azimuth. This research confirmed that attack angle affects with the different azimuth angle that ultimately affect the result of bedding exposed position.

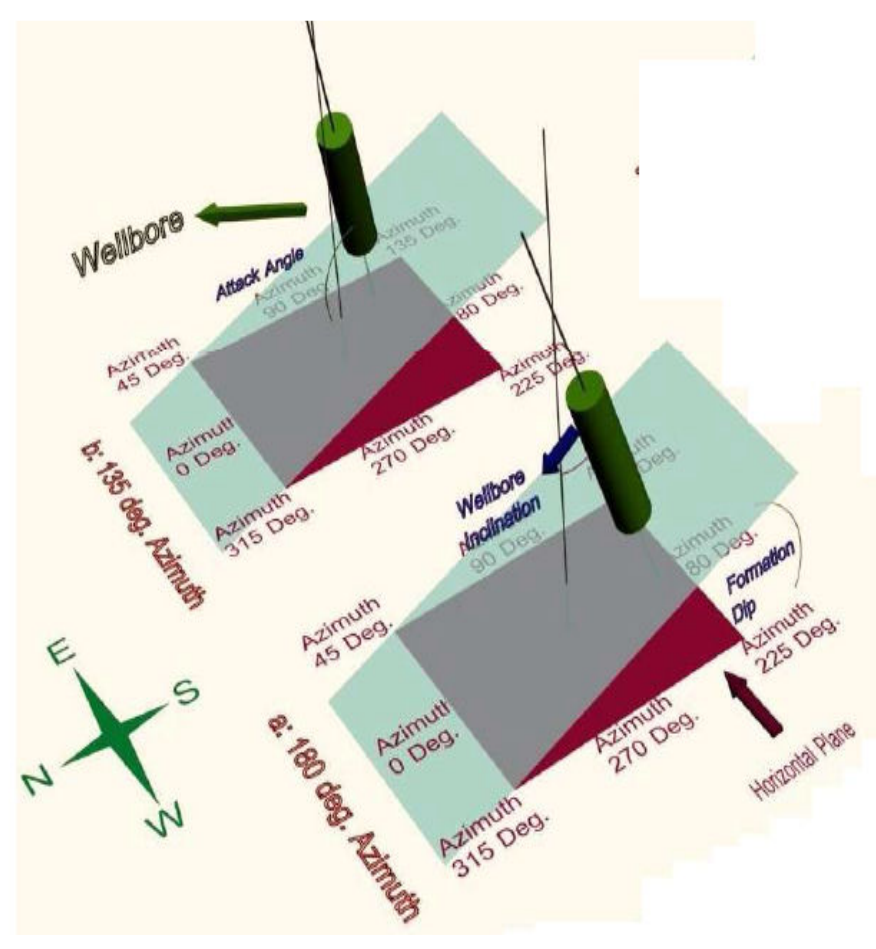

Figure 7. Attack angle Vs azimuth with constant inclination on a bedding Plane 3D - view ${ }^{1}$.

It is establish from the 3D view of Fig. 6 and Fig. 7, attack angle changes with different azimuth although inclination same. Attack angle depends on the relative position of bedding plane, up-dip or down-dip and a plane that contain horizontal stress. So it has to be confirmed what are the dip angle and azimuth before taking the drilling action in to a formation. One should take clear idea about the planes before running Aadnoy model. After introducing the field data into the incorporated model $^{1}$, it is established that this model could be able to determine the optimum well path and know whether the well data is secured or existed on the bedding exposed position. This research analysed the changing of attack angle (3D effect) with different azimuth. This works drew the different azimuth of wellbore position shown in the 3D view of Fig. 7 such as $0^{\circ}, 45^{\circ}, 90^{\circ}, 135^{\circ}, 180^{\circ}, 225^{\circ}, 270^{\circ}$, and $315^{\circ}$.

\section{CONCLUSION AND RECOMMENDATION}

The influencing factors of failure behaviour of anisotropic laminated rocks and wellbore stability can be explained by the Single plane of weakness theory or by variable coefficient approach depending on rock behaviour(Cohesive strength and internal friction). In addition, another influencing factor of wellbore failure, 
the borehole is sensitive to collapse/fracture for a range of 10 to $35^{\circ}$ of inclination to bedding in case of relaxed depositional basins. This may be applicable only to laminated rocks and the phenomenon of plane of weakness. Moreover, if the horizontal in-situ stresses are different, borehole very stable against collapse and it can be drilled by inclining the hole in to the direction of the least in-situ stress. Furthermore, the critical/influencing parameters are plane of weakness in rock strength, relative normal stress values on the borehole, and relative angle between the borehole and bedding plane. For instance, the wells, which are drilled into 0 or 90 degrees of attack angle, are more stable. Moreover, it is also found that relative position of wellbore and bedding plane is more important compared to the rock anisotropy. On the other hand, the attack angle changes with changing azimuth having the inclination unchanged according to the research regarding 3D. So, one should correlate the model (this model) results with the laboratory results before application. This study has replicated Aadnoy et. al model, enhanced their model, and introduced some parameters according to well field case ${ }^{2}$.The most important findings that the user can apply this model whether their field data is on the bedding exposed or safe positions and can get quick result of optimum well path. In addition, this research addressed attack angle with borehole inclination and azimuth relation clearly. Nonetheless, the difference of this research finding regarding up-dip and down-dip positions from those of Aadnoy $^{2}$ field data can be further analysed and justified by means of further study.

\section{Acknowledgements}

I would like to thank Mahbubur Rahaman, Department of PMRE, BUET and Eirik Karstad, University of Stavanger, Norway who have given advice about VBA programming on writing my M.Sc. thesis. I convey plenty of thanks to Manik Chandro Roy, Director, MFAsia, Bangladesh and Nasif Md. Tanjim (Sammo), B.Sc. in Civil engineering, BUET, Bangladesh.

\section{REFERENCES}

1. Shamsuzzoha, Md.,"Analysis of bore hole failure related to bedding plane", Master's thesis, University of Stavanger, Norway June- 2011.

2. Aadnoy B.S., Hareland G., Kustamsi A. , Hajes J. 'Borehole failure related to bedding plane', UiS, University of Calgary, AB, Canada and BG Group, Calgary, AB, Canada. ARMA-09-106, July-2009a.

3. Aadnoy B. S.; Iain Cooper; Stefan Z. Miska; Robert F.Mitchell; and Michael L. Payne.'Advanced Drilling and well Technology'-SPE, Page 301-440, 2009b.

4. Aadnoy, B. S., Chenevert, M.E., "Stability of highly inclined boreholes". InProceedings at the IADC/SPE drilling conference, New Orleans, March 15-18,1987a, SPE16052.

5. AadnoyB.S., 'Stability of highly inclined boreholes' SPE, Rogaland Regional C., , SPE, University of Texas. SPE drilling Engineering, December-1987, SPE-18736.

6. Aadnoy B.S., Chenevert M.E., 'Modeling of the Stability of highly inclined boreholes in anisotropic rock formations', SPE-19213, Rogaland U.,September-1988. 7. Al-Ajmi, A.M. and Zimmerman, R.W., "A new well path optimization model for increased mechanical borehole stability", Int J Pet SciEng 69, 53-62, 2009.

8. Al-Ajmi, A.M. and Zimmerman, R.W.,"Stability Analysis of Deviated Boreholes Using the MogiCoulomb Failure Criterion, With Applications to Some Oil and Gas Reservoirs" presented at the IADC/SPE Asia Pacific Drilling Technology Conference and Exhibition held in Bangkok, 13-15 November-2006a.

9. Chenevert M.E., Gatlin C., 'Mechanical Anisotropies of Laminated Sedimentary Rocks' by, Jr. Member AIME, Member AIME., The University of Texas, Austin, Tex. SPE-890, March-1965.

10. Islam M.A.,'Modeling and Prediction of Borehole Collapse Pressure during Underbalanced Drilling in Shale', PhD Thesis at NTNU, November-2010.

11. Zoback, M.D. 'Reservoir Geo-mechanics', Cambridge University press, ISBN 978-0-521-77069-9, 2010 . 